\title{
What Lies Beneath: The Role of Self-Efficacy, Causal Attribution Habits, and Gender in Accounting for the Success of College Students
}

\author{
Kerstin Hamann ${ }^{1, *(\mathbb{D}}$, Maura A. E. Pilotti ${ }^{2} \mathbb{D}$ and Bruce M. Wilson ${ }^{1}(\mathbb{D}$ \\ 1 School of Politics, Security, and International Affairs, University of Central Florida, Orlando, \\ FL 32816, USA; Bruce.Wilson@ucf.edu \\ 2 College of Sciences and Human Studies, Prince Mohammad Bin Fahd University, \\ Al Khobar 31952, Saudi Arabia; maura.pilotti@gmail.com \\ * Correspondence: Kerstin.Hamann@ucf.edu; Tel.: +1-407-823-2608
}

Citation: Hamann, K.; Pilotti, M.A.E.; Wilson, B.M. What Lies Beneath: The Role of Self-Efficacy, Causal Attribution Habits, and Gender in Accounting for the Success of College Students. Educ. Sci. 2021, 11, 333. https://doi.org/10.3390/ educsci11070333

Academic Editor: James Albright

Received: 4 June 2021

Accepted: 30 June 2021

Published: 5 July 2021

Publisher's Note: MDPI stays neutral with regard to jurisdictional claims in published maps and institutional affiliations.

Copyright: (c) 2021 by the authors. Licensee MDPI, Basel, Switzerland. This article is an open access article distributed under the terms and conditions of the Creative Commons Attribution (CC BY) license (https:/ / creativecommons.org/licenses/by/ $4.0 /)$.

\begin{abstract}
Existing research has identified gender as a driving variable of student success in higher education: women attend college at a higher rate and are also more successful than their male peers. We build on the extant literature by asking whether specific cognitive variables (i.e., self-efficacy and causal attribution habits) distinguish male and female students with differing academic performance levels. Using a case study, we collected data from students enrolled in a general education course (sample size $\mathrm{N}=400$ ) at a large public university in the United States. Our findings indicate that while students' course grades and cumulative college grades did not vary by gender, female and male students reported different self-efficacy and causal attribution habits for good grades and poor grades. To illustrate, self-efficacy for female students is broad and stretches across all their courses; in contrast, for male students, it is more limited to specific courses. These gender differences in cognition, particularly in accounting for undesirable events, may assist faculty members and advisors in understanding how students respond to difficulties and challenges.
\end{abstract}

Keywords: self-efficacy; causal attribution; gender gap; student success

\section{Introduction}

Students' academic success is a common concern among educators and administrators at colleges and universities. In the United States, academic success is often assessed through retention and graduation rates, and the picture is bleak. Many students who enroll in college do not finish at all or do not finish within six years of first taking classes. Just $62 \%$ of all students who first enrolled in college in 2012 graduated from the same institution with a bachelor's degree within six years [1]. The problem of student success is compounded by the fact that many states have tied funding for public universities to performance measures, which generally include retention and graduation rates [2,3]. Although a multitude of factors may cause students to discontinue their college careers, such as the cost of higher education, academic failure plays an important role. Notably, up to $60 \%$ of college students are academically unprepared and not ready for college courses, one of the top five reasons for students to drop out of college [4,5]. Thus, understanding why some students perform better in class than others is of critical importance for calibrating pedagogies and advising strategies to ensure effectiveness. Cognitive variables, such as self-efficacy (i.e., confidence in one's abilities to overcome obstacles and solve problems), may contribute to students' academic success, measured as the accumulation of successes and failures (i.e., grade point average, GPA) or as performance linked to a specific academic setting (e.g., grades in a selected course). For instance, studies have linked self-efficacy to academic success, as selfefficacy is a factor that contributes to self-regulatory behavior, such as study habits [6-8], but the evidence has not been uniformly supportive $[9,10]$. Interestingly, studies have found 
that overall, self-efficacy tends to be higher in male students than in female students [11,12] despite some variability in this pattern [13-16]. At the same time, several studies have highlighted the "gender gap" in higher education, indicating that women compose the majority of college students in the United States [17] and tend to be more successful in college than their male counterparts [18]. Existing research has thus identified gender as a key factor for success in higher education, but exactly how gender shapes academic success is not clear.

In this study, we build on the extant literature by asking whether specific cognitive variables (i.e., self-efficacy and causal attribution habits) distinguish male and female students with differing academic performance levels. In differentiating whether, and how, male and female students' cognitive variables are related to their academic performance, we address a gap in the literature that has established both a gender gap and indicators of variation in self-efficacy and causal attribution habits across male and female students, but has not connected these two factors. We conduct a study of 400 students enrolled in a large public university in the United States to assess these relationships. A better understanding of the relationship between cognitive variables, such as self-efficacy and causal attribution habits, and the academic success of male and female students can inform pedagogical approaches and practices that support students' academic success.

\section{Gender, Self-Efficacy Beliefs, Causal Attribution Habits, and Student Success: An Analytical Framework}

What determines students' success in college? A variety of factors potentially play a role in supporting student achievements, including academic preparation, academic advisement, the rigor of the curriculum and instruction, demographic factors such as age, gender and socioeconomic background, course delivery modality, whether students begin their college career in a four-year institution or transfer from a junior college, whether they have responsibilities outside of college life such as work or family, and whether they live on campus or commute. Yet, among all potential contributors to academic success, gender is not a negligible entity but rather a consistent presence. Across higher education institutions in the USA, the gender gap has displayed two notable trends: women are entering higher education in greater numbers than men, and they are also more successful in college than their male peers. These trends are wide-ranging, including among historically underrepresented demographics, such as Hispanic and African American students [19,20]. To illustrate, more women than men enroll in college shortly after graduating from high school, and when they are in college, male students are approximately $20 \%$ more likely than female students to drop out. Their grades lag behind those of their female peers; and overall, women earn 57.4\% of all Bachelor's degrees [21,22]. In 2019, 65\% of women graduated within six years of starting college, compared to just $59 \%$ of men [1].

Studies have cited several factors to explain this gender gap in higher education, including social support (e.g., family encouragement to pursue educational ambitions), experiences in K-12 education, peer pressure, cultural stereotypes of masculinity, the presence of suitable role models, the availability of employment that does not require a college degree, cognitive development, and self-regulatory behavior [21,22]. For instance, studies have linked students' academic performance to their self-regulatory behaviors, which in turn are conditioned by their self-efficacy beliefs and causal attribution habits. Research has broadly established that students vary with respect to their self-efficacy, a concept developed by Bandura [23]. Yokuyama [24] (pp. 1-2) defines self-efficacy as "an individual's belief in his or her ability to succeed in a specific situation or accomplish a specific task." Learners who have high self-efficacy are assumed to be more motivated to learn and are expected to have higher academic success because they believe in their ability to accomplish what they set out to do [24]. To illustrate, consider students with low self-efficacy who are preparing for an exam. These students are unlikely to believe that they have the ability to do well on the exam. Consequently, they may have little motivation to engage in the kind of self-regulatory behavior that would enhance their chances of success, such as devoting an adequate amount of effort to studying. In contrast, students with 
high self-efficacy, who are confident that they are able to succeed, may be more motivated to engage in self-regulatory behavior since they believe that their actions can impact the likelihood of obtaining the desired outcomes.

One of the factors that differentiate learners' perceptions of self-efficacy is gender and several studies report that female students report lower self-efficacy scores than male students [24-26]. Other studies, however, find that there is no difference in the self-efficacy scores reported by female and male students (see, for example, [27]). The differences in findings may be due to the academic subject matter studied. For instance, a metaanalysis [26] concludes that academic self-efficacy differs for male and female students depending on the subject matter, with male students displaying higher levels than female students in mathematics, computer science, and social sciences, and female students reporting higher levels than male students in language arts. Another meta-analysis [25] finds that self-efficacy varies by gender, especially in STEM disciplines.

Students also vary regarding their causal attribution habits, that is, the factors they credit with and hold accountable for good and poor performance [28]. Learners may attribute their successes or failures to three types of factors: internal or external (i.e., whether the source of an envisioned outcome is within the learner or in the situation that the learner faces), stable or variable (i.e., whether the source is a constant presence in the learner's life or fluctuates), and controllable or uncontrollable (i.e., whether the learner's actions can change the source of an envisioned outcome [29]). For example, some students may credit their success to their own competency or diligence, while others may blame or credit the professor or test when they do poorly or excel, or believe their friends and families were instrumental in their accomplishments or lack thereof.

These causal attribution patterns may also influence students' self-regulatory behavior; that is, their ability to prepare effectively. If students are able to identify causes for performance outcomes they can control, they may be in a better position to achieve academic success. In contrast, if students believe that factors outside of their control are responsible for their performance, they may be less likely to expend efforts to study. Existing research argues that students' academic achievement is related to causal attribution habits -the factors they hold responsible for their successes and failures. Notably, causal attribution habits differ between high and low-achieving learners. For example, one study [30] found that causal attribution habits contribute to students' understanding of their actions in the multitude of academic situations they face, thereby determining not only their selected locus of causality for specific outcomes, but also their sense of stability and personal controllability, exerted effort, and perceived task difficulty. In this study, students who succeed in a mathematics course identified internal factors as the locus of causality, and cited personal controllability; in contrast, students who failed attributed the undesirable outcome to external factors that were externally controllable. Similarly, a different study [31] found that successful students were more likely than unsuccessful students to identify effort and ability as underlying causal mechanisms. Yan and Gaier [32] found that students in the United States credited effort for success but attributed less importance to effort when considering failure; in comparison, Asian students thought that effort was equally important for success as for failure. Causal attribution habits may thus play a significant role in incentivizing students' behavior to support academic success. These studies point to the importance of demographic variables, in particular gender, and cognitive variables such as self-efficacy and causal attribution habits. However, they do not offer conclusive findings about whether male and female students at similar academic achievement levels differ across these cognitive variables. A fine-grained analysis of the interplay of gender and cognitive variables in relation to academic achievement will be useful for understanding how these processes may differ for female and male students and will therefore be helpful in designing appropriate academic interventions. 


\section{This Study}

Our study built on the extant literature by aiming at furthering our understanding of the contribution of cognitive factors to the academic success of male and female students. This study focused on assessing the contribution of students' beliefs in their ability to influence outcomes, including academic performance (general self-efficacy), as well as their dispositions to explain academic successes and failures (causal attribution habits). Specifically, it analyzed the relationship between cognitive variables, such as self-efficacy beliefs and causal attribution habits, and academic success in females and males at a large public university in the United States. We examined two different dimensions of academic success. First, we focused on students' overall performance in college. As such, we operationalized the accumulation of successes and failures in the students' college history as the grade point average (GPA). Second, we measured performance within a particular, temporally defined setting (e.g., a general education course, American National Government). As such, we operationalized academic success as the students' grades in a course. The examination of two different performance outcomes allowed us to assess whether the contribution of the selected cognitive variables is an enduring phenomenon or a fleeting one.

This study was based on a convenience sample consisting of 400 undergraduate students enrolled in 11 sections of an introductory course, American National Government, in the spring 2020 semester at the University of Central Florida. The 11 sections of the class enrolled a total of 621 students; 400 of these students completed the surveys that constitute our dataset. The sample included 130 males and 270 females, a gender ratio that reflects the fact that more female than male students enroll at the selected university. The University of Central Florida is a large public university with a diverse student population. Our sample, which was drawn from the students enrolled in the course, reflected that diversity. Participants identified along ethnic and racial lines as Asian (5.7\%), Black (10.2\%), Hispanic $(28.4 \%)$, White $(42.9 \%)$, or multi-racial $(2.7 \%)$, defined themselves as international $(9.2 \%)$, or did not select any classification $(0.7 \%)$.

As noted above, we employed two measures of academic success. Our first measure, GPA, took into account the entire academic history of the participants, that is, all courses taken during their college career at the time they enrolled in the American Government course, and was thus a measure of overall academic success. Our second measure of academic success focused on a specific class, American National Government, a course that is part of the general education program (GEP) at the selected university. We chose this course for our study because, as a GEP course, it is not specific to any particular major. As such, the course enrolls students from diverse backgrounds whose course grades are unlikely to reflect students' prior expertise in the field of political science. Other considerations also guided our selection of this course: the number of students who completed the course was sufficiently large to allow for meaningful statistical analysis; students did not participate in more than one section of the course; and the learning objectives of the course were consistent across all 11 sections even though four professors taught the different sections. Participation in this study was voluntary for all students 18 years of age or older. Students gave their informed consent to participate prior to the beginning of this study. Students who chose to participate received extra credit after they completed a series of surveys distributed online via their course page. This study was approved by the university's Institutional Review Board and all participants gave their informed consent through an online form. This study also complied with the guidelines set forth by the American Psychological Association's ethical standards in the treatment of human subjects. Demographic and GPA data were provided by the university's Institutional Knowledge Management office.

Data on students' self-efficacy and causal attribution habits were collected by administering two surveys at the beginning of the semester. We used the New General Self-Efficacy (NGSE) inventory $[33,34]$ to measure students' self-reported general confidence in their ability to cope with various life challenges [35]. The inventory assesses students' agreement 
with eight statements gauging general confidence on a scale from strongly disagree (0) to strongly agree (4). Sample statements include "In general, I think that I can obtain outcomes that are important to me", "Compared to other people, I can do most tasks very well", and "I believe I can succeed at most any endeavor to which I set my mind." We assessed students' causal attribution habits (i.e., ordinary explanations of outcomes) in another survey [36]. It asks students to reflect on their best grade and worst grade on a test (i.e., a desirable and undesirable outcome) and rank seven potential reasons that could explain these grades on a scale from 0 (not at all) to 6 (entirely): ability, effort, test difficulty, luck, and the influence of family, instructor, and friends, respectively. At the end of the semester, we recorded students' final course grades on a scale of $0-100$ points, with 0 being the lowest possible grade and 100 the highest possible grade.

\section{Methods, Analysis, and Results}

Our study set out to answer two questions: first, do cognitive variables, such as students' self-efficacy and causal attribution habits, contribute to the overall academic success of male and female students in college, as measured by GPA? Second, are these variables linked to academic success in a particular setting, such as grades in a general education course?

\subsection{Gender Differences}

Prior to the investigation of the potential relationships between our variables, we examined whether our sample reflected gender differences in key demographic, cognitive, and academic success variables (GPA and course grade). Gender differences were examined through ANOVA if a variable was measured at the interval level (e.g., age), or the MannWhitney $U$ test if the variable was measured at the ordinal level (e.g., educational level). No gender differences were detected in key demographic variables, such as age $(M=19.66$, $S E M=0.14), F(1,398)<1$, and educational level (freshman: $30.0 \%$; sophomore: $33.5 \%$; junior: $18.8 \%$; senior: $9.3 \%$; unclassified: $8.4 \%), U=18,221.00, Z=0.64$, $n s$, with the sum of the ranks equal to 195.34 for males and 202.99 for females. Additionally, males and females did not display significantly different GPA, $F(1,398)<1$, $n s$, and course grades, $F(1,398)<1$, ns (see Table 1). Thus, our particular sample of participants did not provide evidence to support the gender gap hypothesis as it pertains to grades.

We then examined whether gender differences were present in cognitive variables, such as general self-efficacy (GSE) and explanatory habits for desirable and undesirable outcomes. We operationalized "desirable outcomes" as those that are generally considered as passing grades, that is, grades that earn an $\mathrm{A}, \mathrm{B}$, or $\mathrm{C}$ grade. In this course, the numeric equivalents were grades in the range of $100-70 \%$. "Undesirable outcomes" were operationalized as equivalent to a D or F grade (69\% or below), which are generally considered "unsuccessful" grades in higher education as they are below the minimum grade point average required for graduation (2.0, equivalent to a $C$ grade).

Table 1 displays descriptive statistics, including means $(M)$ and standard errors of the mean (SEM). We found no evidence that male and female students differed in GSE, $F(1,398)=2.44$, ns. Explanatory habits for desirable and undesirable outcomes, which were submitted to a 2 (gender) X 7 (explanatory habits) $X 2$ (desirable/undesirable grades) mixed factorial ANOVA, revealed a main effect of explanatory habits, $F(6,2388)=555.90$, $M S E=2.30, p<0.001, \eta p^{2}=0.583$, the grade's desirability, $F(1,398)=168.42, M S E=2.43$, $p<0.001, \eta p^{2}=0.297$, and gender, $F(1,398)=5.48, M S E=5.72, p=0.020, \eta p^{2}=0.014$ Namely, students rated some causes (i.e., effort, ability and test) higher than others, and overall higher for desirable than undesirable grades. Furthermore, male students' ratings were higher than those of female students. There were, however, interactions involving explanatory habits and gender, $F(6,2388)=3.43, M S E=2.30, p=0.002, \eta p^{2}=0.009$, explanatory habits and grade desirability, $F(6,2388)=82.55, M S E=1.58, p<0.001, \eta p^{2}=0.172$, and explanatory habits, grade desirability, and gender, $F(6,2388)=2.22, M S E=1.58, p=0.039$, $\eta p^{2}=0.006$ (gender and grade desirability, $F=1.14, n s$ ). Tests of simple effects, which were 
submitted to the Bonferroni correction to control for experiment-wise alpha $(p<0.004)$, were conducted to understand the three-way interaction of explanatory habits, grade desirability, and gender. The only significant gender differences pertained to the finding that males were more likely than females to attribute desirable outcomes to the influence of family and friends (i.e., external, stable influences over which learners have little control).

Table 1. Mean and standard error of the mean of performance, and cognitive variables.

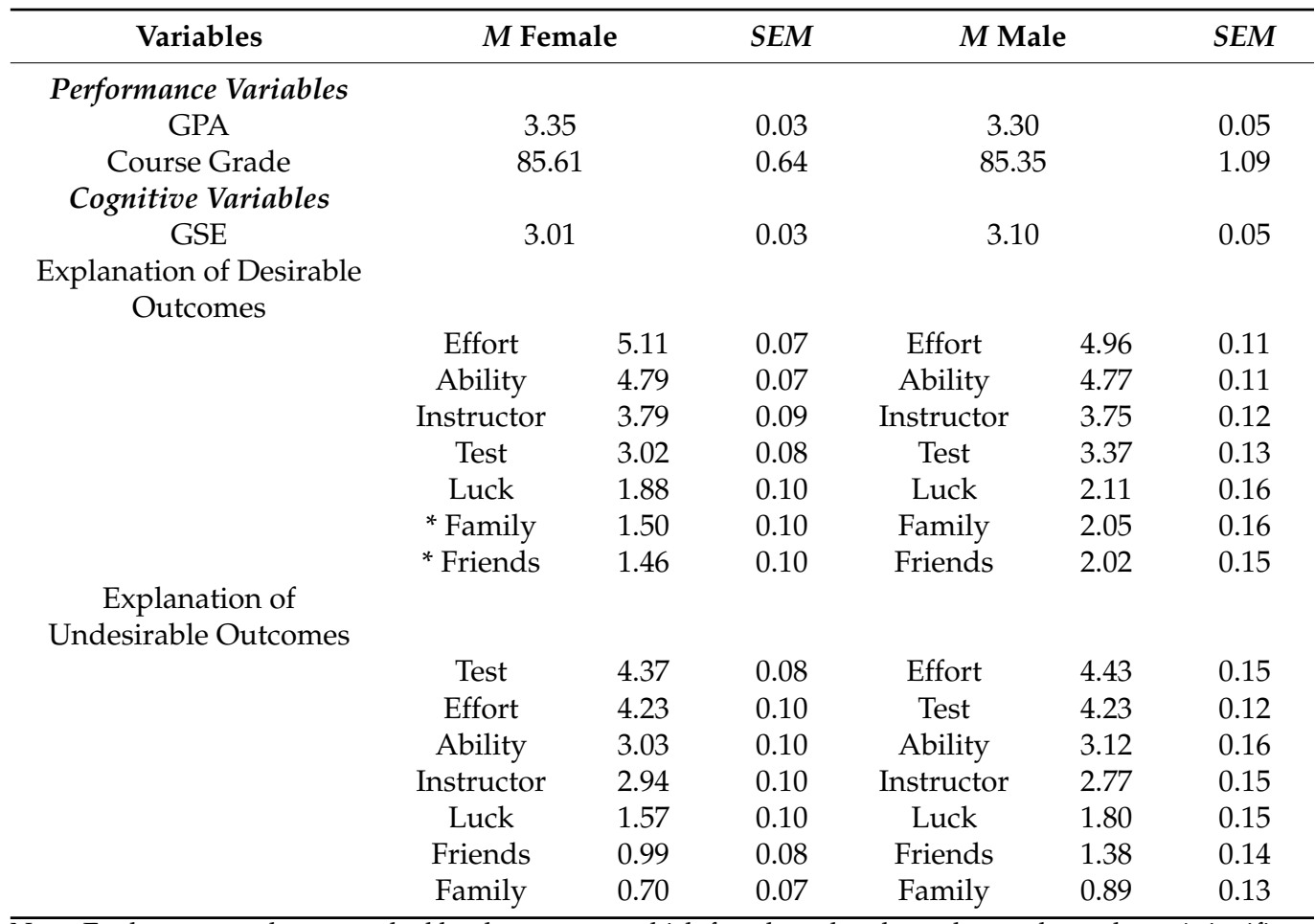

Note: Explanatory styles are ranked by the extent to which female and male students rely on them. ${ }^{*}$ signifies a gender difference in the content of explanatory habits.

Although we found no gender differences in performance defined either as the accumulation of desirable and undesirable outcomes (i.e., GPA) or as a one-time occurrence (i.e., course grades), we asked whether explanatory habits for desirable and undesirable grades and general self-efficacy would contribute to the performance of male and female students differently.

\subsection{The Contribution of Self-Efficacy, Causal Attribution Habits, and Gender to GPA}

Table 2 displays the results of regression analyses of GPA, serving as the outcome variable, and explanatory habits and GSE serving as predictor variables. The $R$ of each model is reported at the bottom of the table. To detect whether differences in explanatory habits existed between male and female students, analyses were conducted separately for desirable and undesirable outcomes explained by each gender. For female students, reliance on effort to explain desirable outcomes was associated with a higher GPA, whereas reliance on (lack of) effort to explain undesirable outcomes was associated with a lower GPA. Furthermore, explaining undesirable outcomes by attributing them to a difficult test or challenging instructor was associated with a higher GPA, whereas attributing such outcomes to luck was associated with a lower GPA. Female students' confidence in their abilities (GSE) contributed to a higher GPA. No significant contribution of either explanatory habits or GSE was detected in males. 
Table 2. Regression analysis with GPA as the outcome variable, and explanatory habits and GSE as the predictors, conducted separately for desirable and undesirable outcomes explained by female and male students.

\begin{tabular}{|c|c|c|c|c|c|}
\hline & $B$ & $S E$ & Beta & $t$ & Sign. \\
\hline \multicolumn{6}{|c|}{ Desirable Outcomes-Females } \\
\hline (Constant) & 2.740 & 0.221 & & & \\
\hline Ability & -0.011 & 0.026 & -0.027 & -0.428 & $n s$ \\
\hline Effort * & 0.075 & 0.026 & 0.185 & 2.865 & 0.005 \\
\hline Test & 0.004 & 0.022 & 0.011 & 0.173 & $n s$ \\
\hline Luck & -0.005 & 0.021 & -0.016 & -0.220 & $n s$ \\
\hline Family & 0.014 & 0.018 & 0.051 & 0.779 & ns \\
\hline Instructor & -0.010 & 0.021 & -0.032 & -0.495 & $n s$ \\
\hline Friends & 0.006 & 0.019 & 0.023 & 0.335 & ns \\
\hline GSE & 0.093 & 0.053 & 0.111 & 1.753 & $n s$ \\
\hline \multicolumn{6}{|c|}{ Desirable Outcome-Males } \\
\hline (Constant) & 2.679 & 0.393 & & & \\
\hline Ability & 0.034 & 0.041 & 0.080 & 0.830 & $n s$ \\
\hline Effort & -0.007 & 0.043 & -0.017 & -0.169 & $n s$ \\
\hline Test & -0.017 & 0.038 & -0.046 & -0.444 & $n s$ \\
\hline Luck & 0.003 & 0.035 & 0.010 & 0.090 & ns \\
\hline Family & 0.042 & 0.028 & 0.147 & 1.494 & ns \\
\hline Instructor & 0.051 & 0.036 & 0.134 & 1.422 & $n s$ \\
\hline Friends & -0.019 & 0.034 & -0.059 & -0.562 & ns \\
\hline GSE & 0.097 & 0.093 & 0.101 & 1.045 & $n s$ \\
\hline \multicolumn{6}{|c|}{ Undesirable } \\
\hline \multicolumn{6}{|c|}{ Outcome-Females } \\
\hline (Constant) & 2.853 & 0.209 & & & \\
\hline Ability & -0.007 & 0.017 & -0.026 & -0.440 & $n s$ \\
\hline Effort* & -0.046 & 0.017 & -0.160 & -2.688 & 0.008 \\
\hline Test * & 0.064 & 0.023 & 0.171 & 2.729 & 0.007 \\
\hline Luck* & -0.042 & 0.020 & -0.144 & -2.105 & 0.036 \\
\hline Family & 0.018 & 0.026 & 0.047 & 0.706 & ns \\
\hline Instructor * & 0.046 & 0.018 & 0.168 & 2.625 & 0.009 \\
\hline Friends & -0.014 & 0.023 & -0.041 & -0.605 & $n s$ \\
\hline$G S E^{*}$ & 0.120 & 0.051 & 0.142 & 2.365 & 0.019 \\
\hline \multicolumn{6}{|c|}{ Undesirable Outcomes-Males } \\
\hline (Constant) & 3.279 & 0.397 & & & \\
\hline Ability & -0.001 & 0.030 & -0.004 & -0.043 & ns \\
\hline Effort & -0.035 & 0.029 & -0.109 & -1.176 & ns \\
\hline Test & -0.019 & 0.043 & -0.048 & -0.441 & $n s$ \\
\hline Luck & 0.020 & 0.037 & 0.064 & 0.540 & $n s$ \\
\hline Family & -0.006 & 0.042 & -0.016 & -0.141 & $n s$ \\
\hline Instructor & 0.020 & 0.036 & 0.065 & 0.550 & ns \\
\hline Friends & -0.049 & 0.038 & -0.147 & -1.285 & ns \\
\hline GSE & 0.076 & 0.093 & 0.080 & 0.819 & $n s$ \\
\hline
\end{tabular}

Note. ${ }^{*}$ Significant contribution. Explanations of desirable outcome by females: $R=0.240$; explanations of desirable outcome by males: $R=0.228$; explanations of undesirable outcome by females: $R=0.362$; explanations of desirable outcome by males: $R=0.202$.

\subsection{The Contribution of Self-Efficacy, Causal Attribution Habits, and Gender to Class Grades}

The same regression analyses conducted on class grade as the outcome variable echoed the relevance of personal effort in female students' performance (see Table 3). Namely, attributing desirable outcomes to one's exerted effort was associated with higher course grades. In contrast, relying on (lack of) effort to explain undesirable outcomes was associated with lower class grades. Furthermore, female students' tendency to explain undesirable outcomes by attributing them to a difficult instructor was associated with higher class grades. For male students, the only significant contribution was that of GSE, which was associated with higher class grades. 
Table 3. Regression analysis with class grade as the outcome variable, and explanatory habits and GSE as the predictors, conducted separately for desirable and undesirable outcomes explained by female and male students.

\begin{tabular}{|c|c|c|c|c|c|}
\hline & $B$ & $S E$ & Beta & $t$ & Sign. \\
\hline \multicolumn{6}{|c|}{ Desirable Outcomes-Females } \\
\hline (Constant) & 74.857 & 5.049 & & & \\
\hline Ability & 0.896 & 0.590 & 0.096 & 1.517 & ns \\
\hline Effort* & 1.300 & 0.599 & 0.141 & 2.172 & 0.031 \\
\hline Test & -0.605 & 0.500 & -0.079 & -1.210 & $n s$ \\
\hline Luck & 0.283 & 0.469 & 0.043 & 0.604 & ns \\
\hline Family & -0.090 & 0.401 & -0.015 & -0.225 & $n s$ \\
\hline Instructor & 0.563 & 0.483 & 0.075 & 1.166 & $n s$ \\
\hline Friends & -0.773 & 0.431 & -0.124 & -1.795 & ns \\
\hline GSE & 0.081 & 1.217 & 0.004 & 0.067 & $n s$ \\
\hline \multicolumn{6}{|c|}{ Desirable Outcome-Males } \\
\hline (Constant) & 71.526 & 8.873 & & & \\
\hline Ability & 1.262 & 0.931 & 0.125 & 1.355 & $n s$ \\
\hline Effort & 0.595 & 0.965 & 0.058 & 0.617 & $n s$ \\
\hline Test & -0.668 & 0.852 & -0.079 & -0.784 & ns \\
\hline Luck & -0.389 & 0.785 & -0.056 & -0.495 & $n s$ \\
\hline Family & 0.190 & 0.640 & 0.028 & 0.297 & $n s$ \\
\hline Instructor & -0.554 & 0.810 & -0.062 & -0.684 & $n s$ \\
\hline Friends & -0.670 & 0.764 & -0.089 & -0.877 & ns \\
\hline GSE & 3.532 & 2.093 & 0.158 & 1.688 & ns \\
\hline \multicolumn{6}{|c|}{ Undesirable } \\
\hline \multicolumn{6}{|c|}{ Outcome-Females } \\
\hline (Constant) & 81.087 & 4.951 & & & \\
\hline Ability & 0.015 & 0.391 & 0.002 & 0.039 & ns \\
\hline Effort * & -0.801 & 0.403 & -0.123 & -1.985 & 0.048 \\
\hline Test & 0.637 & 0.551 & 0.075 & 1.156 & ns \\
\hline Luck & -0.819 & 0.469 & -0.124 & -1.745 & $n s$ \\
\hline Family & 0.062 & 0.612 & 0.007 & 0.101 & $n s$ \\
\hline Instructor * & 1.111 & 0.418 & 0.176 & 2.656 & 0.008 \\
\hline Friends & -0.067 & 0.551 & -0.009 & -0.122 & $n s$ \\
\hline GSE & 1.038 & 1.199 & 0.054 & 0.866 & ns \\
\hline \multicolumn{6}{|c|}{ Undesirable Outcomes-Males } \\
\hline (Constant) & 61.597 & 8.412 & & & \\
\hline Ability & 0.760 & 0.627 & 0.108 & 1.211 & ns \\
\hline Effort & 1.029 & 0.624 & 0.138 & 1.650 & ns \\
\hline Test & 1.203 & 0.920 & 0.129 & 1.308 & ns \\
\hline Luck & 0.007 & 0.784 & 0.001 & 0.009 & $n s$ \\
\hline Family & -1.594 & 0.889 & -0.186 & -1.792 & ns \\
\hline Instructor & -0.494 & 0.759 & -0.070 & -0.650 & ns \\
\hline Friends & -1.287 & 0.815 & -0.164 & -1.579 & $n s$ \\
\hline$G S E^{*}$ & 5.253 & 1.976 & 0.235 & 2.658 & 0.009 \\
\hline
\end{tabular}

Note. ${ }^{*}$ Significant contribution. Explanations of desirable outcome by females: $R=0.236$; explanations of desirable outcome by males: $R=0.341$; explanations of undesirable outcome by females: $R=0.253$; explanations of desirable outcome by males: $R=0.460$.

\section{Discussion and Conclusions}

The results of the current study can be summarized into three key points: first, even though there were no gender differences in students' academic success (as measured by GPA and course grades), and confidence in one's abilities (as measured by GSE), habitual explanations for desirable outcomes slightly differentiated female and male students. To wit, male students, compared to female students, relied more heavily on the influence of friends and family to account for desirable outcomes (e.g., good grades). Second, the contribution of GSE to performance was positive but limited to male students' course grades and female students' GPA. Its influence on performance, however, was visible only when GSE was juxtaposed to explanations of undesirable outcomes. Third, habitual 
explanations of desirable and undesirable outcomes accounted for the performance of male and female students differently. Reliance on effort (an internal, variable, and controllable cause) played a major role in contributing to the GPA and class grades of female students. However, depending on whether effort was used to explain positive or negative outcomes, its influence was either beneficial or detrimental to performance. Female students' reliance on external and stable factors upon which learners have little control to explain undesirable outcomes was positively associated with GPA (i.e., the instructor and the difficulty of a test) and class grades (i.e., the instructor), suggesting that blaming an outside entity for one's negative outcomes may benefit not only current performance but also performance in the long run. However, reliance on luck, a factor that is also external and beyond learners control, but variable, was negatively associated with GPA, suggesting that blaming an outside entity for one's negative outcomes may not always be beneficial to performance if it exemplifies the disposition to give up on oneself. To wit, if a challenge seems random, such as luck, rather than one that can be tackled in the future, students' recognition that an undesirable event is beyond their control can hurt performance across time. The reason may be that it fails to yield to the expectation that the next test will be less difficult or more manageable with the right preparation.

Our study provides a nuanced contribution to the extant literature that has uncovered a gender gap in higher education. By linking academic success to cognitive variables, we have found that although we could not detect a gender gap in students' academic success, the cognitive factors underlying their academic performance varied. Thus, the absence of visible differences in performance between females and males may merely hide some differences in the ways in which female and male learners account for their successes and failures. Acknowledging that male and female students rely on slightly different explanations to account for undesirable events in their lives may help faculty, advisors, and counsels to understand students' responses to serious difficulties and/or mere challenges, and consequently predict when academic persistence is in jeopardy. As such, it can sharpen the effectiveness of interventions targeting students at risk of academic failures [37,38].

The extant literature has reported that female students exhibit better grades in school regardless of the subject matter [18], whereas males perform better on standardized tests, especially when these tests measure quantitative scientific competencies [39,40]. Null gender differences or declines in the magnitude of the differences in standardized tests have also been reported [41,42]. Although our findings are consistent with the evidence of a disappearing gender gap in college students' success, they suggest that disparities lie beneath.

The positive contribution of self-efficacy to performance is not surprising if one considers that general self-efficacy reflects a "can do" attitude, which is linked to conscientiousness [33,34], shapes exerted effort, and enables students to adapt effectively to novel and challenging situations $[43,44]$. Yet, the range of the contribution of a general sense of confidence in one's abilities to academic success is different for female and male students. Specifically, for females, it is broad, reaching across different courses (as measured by GPA), whereas for males, it is more limited, contributing to performance in specific courses but not in others. However, in both female and male students, the contribution of self-efficacy is highlighted when it is juxtaposed to explanations of undesirable outcomes. Thus, interventions targeting the self-efficacy of students at risk of academic failure need to recognize the different explanatory habits of males and females, and perhaps implement broader interventions for males.

The current study has limitations to be addressed in future research endeavors. First, it is important to note that our findings were obtained through convenience sampling of students taking a general education course at a large public university in the USA, which may limit their generalizability. For instance, our sample of participants may have included mostly students motivated to do well in college. Thus, although the findings that academic performance did not differentiate between male and female students are consistent with those of other studies reporting null gender differences or recent declines 
in the magnitude of preexisting differences at earlier educational stages [41,42], they may reflect the equivalent motivation to succeed of the current sample of participants. At the same time, students achieved good and poor grades, indicating that it was not just high-performing students who chose to participate.

Second, although we found gender differences in specific causal attributions, we recognize that each attribution is not defined exclusively by the underlying factors to which it allegedly belongs. To clarify the contribution of particular explanations to academic performance, future research will have to examine whether subjective interpretations further differentiate male and female students [45].

Third, individual differences are particularly relevant when students experience failures in academic endeavors. Adaptive responses (either affective-motivational or action-oriented) and maladaptive responses to undesirable outcomes have been found linked to individual differences in self-efficacy beliefs [46]. Albeit no gender differences in self-efficacy were observed, the particular sources of the differential contribution of self-efficacy beliefs to the performance of male and female students are to be further investigated through a combination of quantitative and qualitative methodologies. The examination of such differences can inform educators on the best course of action for remedial interventions.

Fourth, we concur with Dresel et al. [45] (p. 33) that to "fully understand the motivational consequences of an attribution, it is therefore not sufficient for one to merely be aware of their dimensionality; one also must determine the concrete cause and the causal mechanisms bound to it." Our study is an attempt to identify the particular explanations upon which students rely (e.g., effort and ability) to account for their performance, but does not address individual differences in the meaning of the selected explanations and their consequences on cognition and behavior. For instance, consider the hypothetical scenario of a bad grade being attributed to an instructor. The consequences of this attribution on a student's behavior vary depending on its specific meaning. If the instructor is believed to display harsh grading practices, students may contemplate an array of options, such as enhancing their engagement, complaining to the instructor, or withdrawing from the course. Instead, if the same instructor is believed to be poorly suited for teaching, students may contemplate a slightly different set of options, such as launching a formal complaint to administrators, seeking remedial assistance from a competent source, or withdrawing from the course. Each option is an outcome more or less likely to become reality for that student, depending on the decision-making process adopted, which is also sensitive to individual differences [47]. Future research will be devoted to the analysis of individual differences not only in the meaning attributed to explanations but also in decision-making habits to better understand the consequences they might have on cognition and behavior.

Despite these limitations, the current study offers an evidence-based approach to educators who wish to understand the contribution of particular cognitive variables to the academic success of their students. The methodology adopted and the findings obtained here bring to light additional questions that underscore the need to dig deeper into what lies beneath, as well as a way forward in the never-ending quest to better understand student learning and success.

Author Contributions: Conceptualization, K.H., M.A.E.P. and B.M.W.; methodology, K.H., M.A.E.P. and B.M.W.; software, M.A.E.P.; validation, M.A.E.P.; formal analysis, M.A.E.P.; data curation, K.H., M.A.E.P. and B.M.W.; writing—original draft preparation, K.H., M.A.E.P. and B.M.W.; ed version of the manuscript, K.H., M.A.E.P. and B.M.W. All authors have read and agreed to the published version of the manuscript.

Funding: This research received no external funding.

Institutional Review Board Statement: This study was approved by the Institutional Review Board of the University of Central Florida (ID\#: STUDY00001215, approval date 9 January 2020).

Informed Consent Statement: Informed consent was obtained from all subjects involved in the study. 
Data Availability Statement: Data are available upon request.

Acknowledgments: The authors would like to thank the instructors of the classes and the staff members at the University of Central Florida who assisted with the data collection.

Conflicts of Interest: The authors declare no conflict of interest.

\section{References}

1. IES/NCES (Institute of Education Sciences/National Center for Education Statistics). Undergraduate Retention and Graduation Rates. April 2020. Available online: https:/ / nces.ed.gov/programs/coe/indicator_ctr.asp (accessed on 27 October 2020).

2. Li, A.Y. Lessons Learned: A Case Study of Performance Funding in Higher Education. Third Way. 2018. Available online: https:/ / thirdway.imgix.net/pdfs/override/FINAL-LessonsLearned.pdf (accessed on 27 November 2020).

3. Polatajko, M.M.; Monaghan, C.H. Performance funding of United States' public higher education: Impact on graduation and retention rates. In Handbook of Research on Administration, Policy, and Leadership in Higher Education; Mukerji, S., Tripathi, P., Eds.; IGI Global: Hershey, PA, USA, 2017; pp. 496-517.

4. College Stats. n.d. Top Five Reasons for Dropping Out of College. Available online: https://www.yearon.com/blog/5-reasonsstudents-drop-out-of-college-and-how-to-prepare-yourself-for-them (accessed on 27 November 2020).

5. National Center for Policy and Higher Education. Beyond the Rhetoric: Improving College Readiness through Coherent State Policy. 2010. Available online: http:/ / www.highereducation.org/reports/college_readiness/CollegeReadiness.pdf (accessed on 27 November 2020).

6. Majer, J.M. Self-efficacy and academic success among ethnically diverse first-generation community college students. J. Divers. High. Educ. 2009, 2, 243-250. [CrossRef]

7. Pajares, F. Gender and Perceived Self-Efficacy in Self-Regulated Learning. Theory Into Pract. 2002, 41, 116-125. [CrossRef]

8. Roick, J.; Ringeisen, T. Self-efficacy, test anxiety, and academic success: A longitudinal validation. Int. J. Educ. Res. 2017, 83, 84-93. [CrossRef]

9. Ferrari, J.R.; Parker, J.T. High School Achievement, Self-Efficacy, and Locus of Control as Predictors of Freshman Academic Performance. Psychol. Rep. 1992, 71, 515-518. [CrossRef]

10. Lindley, L.D.; Borgen, F.H. Generalized Self-Efficacy, Holland Theme Self-Efficacy, and Academic Performance. J. Career Assess. 2002, 10, 301-314. [CrossRef]

11. Löve, J.; Moore, C.D.; Hensing, G. Validation of the Swedish translation of the general self-efficacy scale. Qual. Life Res. 2012, 21, 1249-1253. [CrossRef]

12. Aboalshamat, K.; Hou, X.-Y.; Strodl, E. Psychological well-being status among medical and dental students in Makkah, Saudi Arabia: A cross-sectional study. Med. Teach. 2015, 37, S75-S81. [CrossRef]

13. Busch, T. Gender Differences in Self-efficacy and Academic Performance among Students of Business Administration. Scand. J. Educ. Res. 1995, 39, 311-318. [CrossRef]

14. Scholz, U.; Doña, B.G.; Sud, S.; Schwarzer, R. Is General Self-Efficacy a Universal Construct? Psychometric findings from 25 countries. Eur. J. Psychol. Assess. 2002, 18, 242-251. [CrossRef]

15. Schwarzer, R.; Mueller, J.; Greenglass, E. Assessment of perceived general self-efficacy on the internet: Data collection in cyberspace. Anxiety Stress. Coping 1999, 12, 145-161. [CrossRef]

16. Wilson, D.; Freed, L.J.; Shaffer, J. Differences in self-efficacy: Is it women or is it engineering? Presented at the WEPAN National Conference: Advancing Women: Transforming Engineering Education, Seattle, WA, USA, 21 June 2011.

17. Jacob, B.A. Where the boys aren't: Non-cognitive skills, returns to school and the gender gap in higher education. Econ. Educ. Rev. 2002, 21, 589-598. [CrossRef]

18. Voyer, D.; Voyer, S.D. Gender differences in scholastic achievement: A meta-analysis. Psychol. Bull. 2014, 140, 1174-1204. [CrossRef] [PubMed]

19. Garibaldi, A.M. The Expanding Gender and Racial Gap in American Higher Education. J. Negro Educ. 2014, 83, 371-384. [CrossRef]

20. Hayes, D.; Cunningham, M.; Courseault, J. Race-related barriers for African American males pursuing higher education: Implications for psychology. Race Gend. Cl. 2006, 13, 124-132.

21. Mintz, S. The Other Gender Gap. Inside Higher Ed. 4 August 2019. Available online: https://www.insidehighered.com/blogs / higher-ed-gamma / other-gender-gap (accessed on 27 November 2020).

22. Semuels, A. Poor Girls Are Leaving Their Brothers behind. The Atlantic, 27 November 2017. Available online: https:/ www theatlantic.com/business/archive/2017/11/gender-education-gap/546677/ (accessed on 10 October 2020).

23. Bandura, A. Self-efficacy: Toward a unifying theory of behavioral change. Psychol. Rev. 1977, 84, 191-215. [CrossRef]

24. Yokoyama, S. Academic Self-Efficacy and Academic Performance in Online Learning: A Mini Review. Front. Psychol. 2019, 9 , 2794. [CrossRef]

25. Byars-Winston, A.; Diestelmann, J.; Savoy, J.N.; Hoyt, W.T. Unique effects and moderators of effects of sources on self-efficacy: A model-based meta-analysis. J. Couns. Psychol. 2017, 64, 645-658. [CrossRef]

26. Huang, C. Gender differences in academic self-efficacy: A meta-analysis. Eur. J. Psychol. Educ. 2012, 28, 1-35. [CrossRef] 
27. Jordan, K.; Carden, R. Self-Efficacy and Gender in STEM Majors. Mod. Psychol. Stud. 2017, 22, 60-64. Available online: https://scholar.utc.edu/mps/vol22/iss2/8 (accessed on 10 October 2020).

28. Weiner, B. The Development of an Attribution-Based Theory of Motivation: A History of Ideas. Educ. Psychol. 2010, 45, 28-36. [CrossRef]

29. Weiner, B. Intrapersonal and Interpersonal Theories of Motivation from an Attribution Perspective. In Student Motivation; Salili, F., Chiu, C.Y., Hong, Y.Y., Eds.; Springer: Boston, MA, USA; pp. 17-30. [CrossRef]

30. Cortés-Suárez, G.; Sandiford, J.R. Causal Attributions for Success or Failure of Students in College Algebra. Community Coll. J. Res. Pr. 2008, 32, 325-346. [CrossRef]

31. Griffin, B.Q.; Combs, A.L.; Land, M.L.; Combs, N.N. Attribution of Success and Failure in College Performance. J. Psychol. 1983, 114, 259-266. [CrossRef]

32. Yan, W.; Gaier, E.L. Causal Attributions for College Success and Failure: An Asian-American comparison. J. Cross-Cult. Psychol. 1994, 25, 146-158. [CrossRef]

33. Chen, G.; Gully, S.M.; Eden, D. Validation of a New General Self-Efficacy Scale. Organ. Res. Methods 2001, 4, 62-83. [CrossRef]

34. Chen, G.; Gully, S.M.; Whiteman, J.-A.; Kilcullen, R.N. Examination of relationships among trait-like individual differences, state-like individual differences, and learning performance. J. Appl. Psychol. 2000, 85, 835-847. [CrossRef]

35. Bandura, A. Human agency in social cognitive theory. Am. Psychol. 1989, 44, 1175-1184. [CrossRef]

36. McClure, J.; Meyer, L.H.; Garisch, J.; Fischer, R.; Weir, K.F.; Walkey, F.H. Students' attributions for their best and worst marks: Do they relate to achievement? Contemp. Educ. Psychol. 2011, 36, 71-81. [CrossRef]

37. Cue, E.N.; Taylor, A.Z. Modifying Harmful Beliefs About Academic Setbacks: An Attribution Retraining Intervention for African-American Middle School Students at Risk for Academic Failure. J. Educ. Dev. 2020, 4, 30-45. [CrossRef]

38. Perry, R.P. Perceived (Academic) Control and Causal Thinking in Achievement Settings. Can. Psychol. Can. 2003, 44, 312-331. [CrossRef]

39. Akpotor, J.; Egbule, E.O. Gender Difference in the Scholastic Achievement Test (SAT) among School Adolescents. World J. Educ. 2020, 10, 97-101. [CrossRef]

40. Hedges, L.V.; Nowell, A. Sex differences in mental test scores, variability, and numbers of high-scoring individuals. Science 1995, 269, 41-45. [CrossRef] [PubMed]

41. Else-Quest, N.M.; Hyde, J.S.; Linn, M.C. Cross-national patterns of gender differences in mathematics: A meta-analysis. Psychol. Bull. 2010, 136, 103-127. [CrossRef]

42. Feingold, A. Cognitive gender differences are disappearing. Am. Psychol. 1988, 43, 95-103. [CrossRef]

43. Judge, T.A.; Erez, A.; Bono, J.E. The Power of Being Positive: The Relation Between Positive Self-Concept and job Performance. Hum. Perform. 1998, 11, 167-187. [CrossRef]

44. Pulakos, E.D.; Arad, S.; Donovan, M.A.; Plamondon, K.E. Adaptability in the workplace: Development of a taxonomy of adaptive performance. J. Appl. Psychol. 2000, 85, 612-624. [CrossRef] [PubMed]

45. Dresel, M.; Schober, B.; Ziegler, A. Nothing More Than Dimensions? Evidence for a Surplus Meaning of Specific Attributions. J. Educ. Res. 2005, 99, 31-45. [CrossRef]

46. Grassinger, R.; Dresel, M. Who learns from errors on a class test? Antecedents and profiles of adaptive reactions to errors in a failure situation. Learn. Individ. Differ. 2017, 53, 61-68. [CrossRef]

47. Burnett, P.C.; Mann, L.; Beswick, G. Validation of the flinders decision making questionnaire on course decision making by students. Aust. Psychol. 1989, 24, 285-292. [CrossRef] 